James E. Freije, M.D., Jack L. Gluckman, M.D., Harry VanLoveren, M.D., John J. McDonough, M.D. and Kevin A. Shumrick, M.D.

\title{
Reconstruction of the Anterior Skull Base After Craniofacial Resection
}

\begin{abstract}
Significant controversy continues as to how best to reconstruct anterior skull base defects after craniofacial resection with a view to minimizing the postoperative morbidity. Techniques varying from simple skin grafts to local and pedicled flaps, as well as bone harvested from a variety of sources have all been proposed. Careful review of the literature combined with personal experience with 34 anterior skull base defects following tumor surgery are presented in an attempt to develop a decision-making process to determine the ideal reconstructive technique for various situations. (Skull Base Surgery, Volume 2, Number 1, 1992, p. 17)
\end{abstract}

Ketcham et al ${ }^{1,2}$ have been credited with popularizing the craniofacial approach for tumors of the paranasal sinuses and anterior skull base. These techniques have evolved and become refined to a point where safe en bloc resection of cancers previously considered unresectable can be performed with improved survival rates. ${ }^{2}$ As the indications and, concomitantly, the extent of the resection expands, the associated morbidity and even mortality become of great concern. Key to diminishing the complication rate is the judicious use of reconstructive techniques that have likewise increased in sophistication. The ideal technique for skull base reconstruction in any given situation is unclear, with possibilities ranging from no formal reconstruction, particularly if the defects are small, to sophisticated free flaps with microvascular anastomosis in larger defects.

The purpose of this article is to review the literature dedicated to this topic and our own experience in 34 patients who underwent anterior craniofacial resection at the University of Cincinnati Medical Center from 1975 to 1990 and attempt to determine whether a logical approach to reconstruction could be developed.

\section{MATERIALS AND METHODS}

From September 1975 to October 1990, 34 patients at the University of Cincinnati Medical Center who underwent anterior craniofacial resection for tumors of the skull base are included in this study. It should be noted that the vast majority of these cases were performed in recent years and that the reconstructive techniques used were frequently governed by the era in which the surgery was performed. These procedures were performed on various benign and malignant tumors involving the anterior skull base. Table 1 lists the sites of the lesions, with the pathologic lesions identified in Table 2.

Of these 34 patients, 15 had resections confined to the anterior skull base, with the remainder having more extensive resections extending to the middle cranial fossa, infratemporal fossa, etc. Orbital exenteration was performed in 15 patients and in seven a radical maxillectomy was performed. Dural or limited frontal lobe involvement was not considered to be a surgical contraindication, depending on the pathologic condition encountered, and

Skull Base Surgery, Volume 2, Number 1, January 1992 Department of Otolaryngology and Maxillofacial Surgery, Department of Neurosurgery, and Department of Surgery, University of Cincinnati Medical Center, Cincinnati, Ohio Reprint requests: Dr. Jack L. Gluckman, University of Cincinnati Medical Center, Department of Otolaryngology, 231 Bethesda Avenue, Cincinnati, Ohio 45267-0528 Copyright (C) 1992 by Thieme Medical Publishers, Inc., 381 Park Avenue South, New York, NY 10016. All rights reserved. 
Table 1. Site of Tumors

\begin{tabular}{lc}
\hline Site & Number \\
\hline Ethmoid sinus & 12 \\
Maxillary sinus & 4 \\
Periorbita & 5 \\
Nasal cavity & 5 \\
Nasopharynx & 5 \\
Sphenoid sinus & 3 \\
\hline
\end{tabular}

Table 2. Pathologic Diagnosis

\begin{tabular}{lc}
\hline Pathology & Number \\
\hline Squamous cell carcinoma & 7 \\
Undifferentiated carcinoma & 1 \\
Adenoid cystic carcinoma & 5 \\
Adenocarcinoma & 4 \\
Esthesioneuroblastoma & 3 \\
Mucoepidermoid carcinoma & 1 \\
Malignant schwannoma & 1 \\
Transitional cell carcinoma & 1 \\
Craniopharyngioma & 1 \\
Meningioma & 3 \\
Angiofibroma & 3 \\
Desmoplastic fibroma & 1 \\
Inverting papilloma & 1 \\
Neurofibroma & 1 \\
Psammomatoid ossifying fibroma & 1 \\
\hline
\end{tabular}

these structures were included in the intracranial extirpation if indicated. Five patients had received radiation therapy with or without chemotherapy prior to surgical treatment and 14 patients underwent postoperative radiation therapy.

\section{RESULTS}

Table 3 lists the reconstructive techniques and complications encountered following the craniofacial resection. Four patients with small anterior skull base defects and intact dura underwent no reconstruction. In 16 patients, reconstruction with a simple split-thickness skin graft placed over the dura was performed with no additional augmentation of the skull base. Local flaps were utilized in seven patients, consisting of five temporalis muscle flaps and two pericranial flaps. In three patients who underwent extended anterolateral resection, free flaps were used for both structural support and improved aesthetics. Of the 34 patients in the series, repair of bony defects were undertaken in only two cases.

Postoperative complications possibly related to the repair consisted of four cerebrospinal leaks; one patient subsequently had meningitis and died and two patients had postoperative pneumocephalus. In two patients with cerebrospinal fluid (CSF) leaks and one case of tension pneumocephalus, surgical intervention was necessary. There were no overt failures of skin grafts, pedicled flaps, or free flaps in any of these patients.

\section{DISCUSSION}

Craniofacial resection has become a well-accepted approach to neoplasms of the anterior skull base, but confusion still exists as to the ideal technique needed to close the defect created. The major reason for this appears to be because no single center has attained a large enough experience to standardize their approach and the literature is replete with descriptions of a wide variety of techniques for various defects. Final choice of technique is invariably governed by individual prejudice based on limited per-

Table 3. Method of Reconstruction and Complications

\begin{tabular}{|c|c|c|}
\hline & Number & Complication \\
\hline \multicolumn{3}{|l|}{ Intact dura } \\
\hline No reconstruction & 4 & 0 \\
\hline Split-thickness skin graft & 16 & Pneumocephalus (1) \\
\hline \multicolumn{3}{|l|}{ Dural defect } \\
\hline \multicolumn{3}{|l|}{ Patch } \\
\hline Fascia lata & 2 & Cerebrospinal fluid leak (1) \\
\hline Homograft & 1 & 0 \\
\hline \multicolumn{3}{|l|}{ Soft tissue augmentation } \\
\hline Pericranial flap & 1 & 0 \\
\hline Temporalis flap & 2 & Cerebrospinal fluid leak/meningitis and death (1) \\
\hline Rectus flap & 1 & 0 \\
\hline \multicolumn{3}{|l|}{ Patch + soft tissue augmentation } \\
\hline Temporalis flap + split-thickness skin graft & 3 & Cerebrospinal fluid leak (1) \\
\hline Rectus flap + fascia lata & 1 & Cerebrospinal fluid leak \\
\hline Latissimus flap + split-thickness skin graft & 1 & 0 \\
\hline \multicolumn{3}{|l|}{ Patch + bone augmentation } \\
\hline Homograft dura + iliac bone graft + fascia lata & 1 & 0 \\
\hline \multicolumn{3}{|l|}{ Patch + bone and soft tissue augmentation } \\
\hline Fascia lata + split calvarial bone + pericranial flap & 1 & Pneumocephalus \\
\hline
\end{tabular}


sonal experience and facilities available. In addition, on analysis of the literature devoted to this topic, many of the reconstructive techniques described are devoted more to cosmetic appearance than the reconstruction of the skull base per se.

The purpose of any reconstruction is to attain a watertight seal between the intracranial space and the upper respiratory system; to supply adequate structural support for the intracranial contents, thereby preventing brain herniation into the surgical defect; and, finally but secondarily, to achieve optimal cosmesis. Attaining the first goal is imperative in order to diminish the risk of CSF leak and intracranial sepsis.

Review of the literature in attempting to evaluate reconstructive techniques is difficult to interpret. In Ketcham et al's initial series reported in $1963^{1}$ and in a followup study in $1973,{ }^{2}$ the anterior skull base defect was reconstructed using only a split-thickness skin graft placed on dura with no significantly increased complication rate associated with this simplistic approach. Dural defects were either closed primarily or with temporalis fascia graft prior to skin grafting. They did, however, identify one case early in their series in which an intradural abscess was attributed to failure of the reconstructive technique where skin graft was placed on a free temporalis fascia graft. ${ }^{1}$ Schramm et al $^{3}$ reporting in 1979 likewise used skin grafts over intact dura, but if a dural defect required grafting with fascia lata, they advocated placing a pedicled galeal flap over the graft before applying the skin graft to ensure graft take over a vascularized bed. All these workers concurred that no bony augmentation of the skull base defect was necessary.

Concerns that skin graft coverage alone of the dura may not suffice, particularly if the dura has to be patched, has prompted the use of various flaps to provide a better barrier between the intracranial contents and the upper respiratory tract. In 1965, Edgerton and Snyder ${ }^{4}$ described the use of a two-stage split scalp flap to close the anterior skull base defect. This innovative approach consisted of rotating a scalp flap based on the superficial temporal artery over the exposed dura. After 3 weeks, the hair-bearing portion of the scalp flap is returned to its original site, leaving the denuded deep layer of the flap, which is subsequently skin grafted. Other workers have described using regional scalp and traditional forehead flaps to reconstruct the anterior skull base. ${ }^{5-7}$ Ousterbout and Tessier ${ }^{8}$ described a midline forehead flap based on the angular artery to close limited anterior skull base defects. The proximal pedicle of the flap is deepithelialized and the flap sutured to the bony margins of the defect. The donor site is closed primarily with minimal cosmetic deformity. Although these forehead flaps are quite reliable and successful in walling off the intracranial contents, limited mobility of these flaps, together with the additional regional cosmetic deformity, has not led to wide acceptance.

The flaps most popular today are a variety of subcutaneous and muscle scalp flaps. The axial subcutaneous scalp flap as described by Schafer et al ${ }^{9}$ is based on the superficial temporal as well as the supraorbital and supratrochlear vessels. This is an excellent flap for reconstruction of large anterior skull base defects and, of course, has no donor site defect.

Probably the most popular method of reconstructing the anterior skull base today is the pericranial flap. ${ }^{10-15}$ This is based on the superficial temporal, supratrochlear, and supraorbital arteries. After a standard bicoronal incision is performed, a scalp flap is elevated in the subgaleal plane to the level of the supraorbital rims. At this point, the pericranium is incised and the dissection carried forward in this plane preserving the blood supply from the supratrochlear and supraorbital arteries. After the craniofacial resection is complete, the pericranial flap is rotated through the craniotomy. It may be sutured to the posterior remnant of dura if a portion of dura has been resected or it may be secured by wedging it between dura and bone with pieces of Gelfoam. The pericranial flap therefore may be used to repair dural defects or can augment the intact or reconstructed dura by providing support and, because of its vascularity, is an excellent recipient site for skin grafting. Modifications of the pericranial flap include the galeal-pericranial ${ }^{16}$ and galeal frontalis myofacial flaps, ${ }^{17}$ which add additional fascial layers to the pericranial flap, thereby giving more substance to the flap and augmenting its blood supply. There is, however, a greater chance of damage to the hair follicles. More currently, Snyderman et al ${ }^{18}$ reported excellent results using galeal and pericranial flaps alone for anterior cranial base reconstruction.

The temporalis muscle flap is a reliable and easily harvested transposition flap that is particularly useful in defects that include an orbital exenteration, ${ }^{19,20}$ but can be used to close standard anterior skull base defects. A routine coronal incision allows access to the muscle. The muscle with its investing fascia is elevated from above downward. Its fascial attachment to the zygomatic arch is divided, but its attachment to the coronoid process is preserved to protect the blood supply. Because of its excellent blood supply, the flap is a good recipient for skin grafting. Although the flap is very convenient, the ability to rotate it is somewhat limited, although the flap can be lengthened by filleting.

In recent years, free flaps have been advocated for reconstruction of extensive anterior skull base defects, particularly if orbital exenteration and extensive facial skin excision have occurred. These flaps supply virtually unlimited tissue for reconstruction, thereby sealing off the cranial cavity. A relative disadvantage is that free flaps do add significant length to the operative procedure. The rectus abdominus and latissimus dorsi free flaps ${ }^{21,22}$ appear to be the most popular at this time, with the design of these flaps limited only by the imagination of the skull base surgeon. The tensor fascia lata free flap ${ }^{23,24}$ has also been described for skull base reconstruction. This flap is based on the terminal branch of the lateral circumflex femoral artery, which supplies the tensor fascia lata mus- 
cle, a portion of the iliac crest, and the overlying skin on the anterolateral aspect of the thigh. A vascular pedicle of 6 to $7 \mathrm{~cm}$ can be developed for anastomosis to the facial vessels.

Various free composite grafts ${ }^{25}$ have also been described for reconstruction of the skull base, thereby allowing the inclusion of bone for reconstruction.

The unrestricted movement of these free flaps, as well as their ability to provide ample support and tissue bulk to cover large defects, make this type of repair ideal after very extensive resections. Although covering these defects with bulky flaps may impede the detection of early recurrence of the cancer, the functional and cosmetic advantages far outweigh this disadvantage since routine magnetic resonance imaging or computed tomography scans are effective for following these patients.

The need for bony reconstruction of the skull base to prevent brain herniation is the source of some controversy and has been advocated by some authors.9,26 Schuller et al ${ }^{26}$ emphasized the need to provide rigid bony support using split rib grafts supplemented with a vascularized pericranial flap or split-thickness skin graft. Other sources of bone include calvarial bone and iliac crest. Against the use of bone grafts is that these grafts potentially predispose to infection, tend to absorb with time, and are not necessary because brain herniation does not seem to be a problem.

Our experience at the University of Cincinnati consisted of a wide variety of reconstructive techniques with the selection of the technique depending on the situation encountered and the philosophy of the surgeon at that particular moment in time. An attempt to determine the optimal reconstructive technique using the complication rate encountered was not entirely successful because of the diverse number of techniques employed and the small number of cases in each group. Only a total of four CSF leaks developed postoperatively and these leaks appeared to be related more to the extent of disease encountered and the size of the resection rather than the method of repair utilized. The two cases of pneumocephalus encountered occurred in one patient repaired with a skin graft and another with a pericranial flap. Certainly in one case, premature removal of the nasal packing was thought to be a contributing cause. Meningitis with subsequent death developed in one patient with CSF leak who had an extensive craniopharyngioma resected and whose defect was repaired with a temporalis muscle flap. It was thought that this flap was inadequate and a larger free flap would have been a better choice.

Based on review of the literature and our personal experience, the following approach to reconstruction of the anterior skull base is suggested.

1. Every attempt should be made to delineate preoperatively the type and extent of lesion to be resected. This will aid in determining the amount of skull base to be resected and therefore the reconstructive options that should be considered. No matter how careful the preopera- tive planning, the surgeon should be prepared for any eventuality and, if possible, have all reconstructive options open. As a prelude to surgery, a lumbar drain should be placed and left in situ for 3 to 5 days postoperatively. 15,27

2. Even if the dura is not involved and is elevated intact, small defects are still present where the olfactory nerves traverse the dura, and these defects need to be looked for and sutured to obtain a watertight seal. Once this has been successfully accomplished, a simple splitthickness skin graft on the nasal side is probably all that is necessary for reinforcement to prevent CSF leak. If the skull base defect is greater than $2 \mathrm{~cm}$ or if there is concern that a skin graft is not sufficient, a pericranial flap or temporalis muscle flap should be placed over the dura and then skin grafted on the nasal side. Of the two, the pericranial flap is easier to harvest and the temporalis muscle better if a bulkier flap is needed or the orbital contents have been removed. This flap may be secured with sutures to the dura or simply wedged between the dura and bony shelf. Nasal packing should be left in place for at least 5 days.

3. If a portion of the dura is resected. Fascia lata or temporalis fascia should be harvested and used as a dural patch using interlocking 5-0 silk suture. This must be reinforced with a vascularized pericranial or temporalis muscle flap prior to the application of the skin graft to ensure an adequate seal. In addition, an occlusive nasal pack should be placed for at least 5 days in an attempt to prevent pneumocephalus.

4. It is our opinion that closure of skull base defects with bone is unnecessary. The support obtained from the pericranial flap or temporalis muscle flap appears to be more than adequate to prevent brain herniation even with large defects. In addition, rib or iliac crest bone grafts may be difficult to harvest ${ }^{10}$ and may add significant morbidity to the procedure. Bone grafts may also become a potential source of infection.

5. When a significantly larger defect is present, particularly if orbital exenteration and significant facial skin has been excised, a bulky muscle flap needs to be placed. Although a temporalis muscle flap with an overlying skin graft may suffice, either a latissimus dorsi or rectus abdominus free flap should be used.

In summary, the methods of anterior skull base reconstruction vary considerably between centers and surgeons. Based on our review of the literature, as well as our own experience, we have attempted to develop some guidelines for determining an approach to reconstruction of anterior skull defects that, hopefully, will prove to be of value to the practicing skull base surgeon.

\section{REFERENCES}

1. Ketcham AS, Wilkins RH, Van Buren JM, et al: A combined intracranial facial approach to the paranasal sinuses. Am J Surg 106:698-703, 1963 
2. Ketcham AS, Chretien PB, Van Buren JM, et al: The ethmoid sinuses: A re-evaluation of surgical resection. Am J Surg 126: 469-476, 1973

3. Schramm VL, Myers EN, Maroon JC: Anterior skull base surgery for benign and malignant disease. Laryngoscope 89:1077-1091, 1979

4. Edgerton MT, Snyder GB: Combined intracranial-extracranial approach and use of the two stage split flap technique for reconstruction with craniofacial malignancies. Am J Surg 110:595602,1965

5. Wilson JSP, Westbury G: Combined craniofacial resection for tumor involving the orbital walls. Br J Plast Surg 26:44-56, 1973

6. Westbury G, Wilson JSP, Richardson A: Combined craniofacial resection for malignant disease. Am J Surg 130:463-469, 1975

7. Terz JJ, Young HG, Lawrence W Jr: Combined craniofacial resection for locally advanced carcinoma of the head and neck. Am J Surg 140:618-624, 1980

8. Ousterbout DK, Tessier P: Closure of large cribiform defects with a forehead flap. J Maxillofac Surg 9:7-9, 1981

9. Schaefer SD, Close LG, Mickey BE: Axial subcutaneous scalp flaps in the reconstruction of the anterior cranial fossa. Arch Otolaryngol-Head Neck Surg 112:745-749, 1986

10. Shah JP, Galicich JH: Craniofacial resection for malignant tumors of ethmoid and anterior skull base. Arch Otolaryngol 103:514517,197

11. Johns ME, Winn HR, McLean WC, et al: Pericranial flap for closure of defects of craniofacial resections. Laryngoscope 98 $1159-1164,1988$

12. Sundoresan N, Shah JP: Craniofacial resection for anterior skull base tumors. Head Neck Surg 10:219-224, 1988

13. Blacklock JB, Weber RS, Lee YY, et al: Transcranial resection of tumors of the paranasal sinuses and nasal cavity. J Neurosurg 71: 10-15, 1989

14. Stiernberg CM, Bailey BJ, Weiner RL, et al: Reconstruction of the anterior skull base following craniofacial resection. Arch Otolaryngol-Head Neck Surg 113:710-712, 1987

15. Horowitz JH, Persing JA, Nichter LS, et al: Galeal-pericranial flaps in head and neck reconstruction. Am J Surg 148:489-497, 1984

16. Jackson IT, Adham MN, Marsh WR: Use of the galeal frontalis myocutaneous flap in craniofacial surgery. Plast Reconstr Surg 77:905-910, 1985

17. Snyderman CH, Janecka IP, Sekhar LN, et al: Anterior cranial base reconstruction: Role of galeal and pericranial flaps. Laryngoscope 100:607-614, 1990

18. Holms AD, Marshall KA: Uses of the temporalis muscle flap in blanking out orbits. Plast Reconstr Surg 63:336-343, 1979

19. Bakamjian VY, Souther SG: Use of temporal muscle flap for reconstruction after orbito-maxillary resections for cancer. Plast Reconstr Surg 56:171-177, 1975

20. Barrow DL, Nahai F, Fleischer AS: Use of free latissimus dorsi musculocutaneous flaps in various neurosurgical disorders. J Neurosurg 58:252-258, 1983

21. Baker SR: Closure of large orbito-maxillary defects with free latissimus dorsi myocutaneous flaps. Head Neck Surg 6:828835,1984

22. Bridger GP, Baldwin M, Gonski A: Craniofacial resection for paranasal sinus cancer with free flap repair. Aust NZ J Surg 56: 843-847, 1986

23. Bridger GP, Baldwin M: Anterior craniofacial resection for ethmoid and nasal cancer with free flap reconstruction. Arch Otolaryngol-HN Surg 115:308-312, 1989

24. Richards MA: Free composite reconstruction of a complex craniofacial defect. Aust NZ J Surg, 57:129-132, 1987

25. Schuller DR, Goodman JH, Miller CA: Reconstruction of the skull base. Laryngoscope 94:1359-1364, 1984

26. Aitken RR, Drake CG: Continuous spinal drainage in the treatment of postoperative cerebrospinal fluid fistulae. J Neurosurg 21: 275-277, 1974 